\title{
A seroepidemiological survey of Crimean Congo hemorrhagic fever among Cattle in North Kordufan State, Sudan
}

\author{
Ibrahim A Adam, Mubarak AM Mahmoud and Imadeldin E Aradaib*
}

\begin{abstract}
Background: Crimean Congo hemorrhagic fever (CCHF), caused by CCHF virus (CCFV), may cause a fatal hemorrhagic illness in humans with mortality rate of approximately $30 \%$. However, in animals the disease is typically asymptomatic and no clinical hemorrhagic infections appears to be associated with CCHFV. Recently, CCHF activity has been detected in western and southern Kordufan region, Sudan. Currently, no information is available in regard to previous exposure of livestock to CCHFV infection in the region.
\end{abstract}

Aims: In the present study, a seroepidemiological survey was conducted to determine the prevalence of CCHF and to identify the potential risk factors associated with the disease among cattle in North Kordufan State, Sudan.

Methods: In this survey, 299 blood samples were collected randomly from six localities in North Kordufan State and were tested by enzyme-linked immunosorbent assay (ELISA) for detection of CCHFV-specific immunoglobulin $\mathrm{G}(\mathrm{lgG})$ antibodies.

Results: The result of the study indicated that the prevalence rate of CCHF was relatively high among cattle, where serological evidence of the infection was observed in 21 (7.0\%) of 299 animals. Older cattle were eight times more likely to be infected with the virus ( $\mathrm{OR}=8.0824, \mathrm{Cl}=1.174-66.317, \mathrm{p}$-value=0.034). Cross breeds were at 37 time higher at risk compared to endogenous breed $(\mathrm{OR}=37.06, \mathrm{Cl}=1.455-944, \mathrm{p}$-value $=0.029)$. Highly tick-infested cattle are 6 times higher at risk for CCHF when compared to tick-free animals (OR=6.532, $\mathrm{Cl}=1.042-10.852, \mathrm{p}$-value=0.030).

Conclusion: It is recommended that surveillance of CCHF should be extended to include other ruminant animals and to study the distribution of ticks in the region to better predict and respond to CCHF outbreak in the State of North Kordufan, Sudan.

Keywords: Epidemiology, Survey, Viral hemorrhagic fevers, CCHFV, ELISA, Sudan

\section{Introduction}

Crimean-Congo hemorrhagic fever (CCHF) is a tickborne disease caused by CCHF virus (CCHFV) of the genus Nairovirus in the family Bunyaviridae. The CCHFV infection is transmitted to humans by tick bites, handling of ticks, exposure to blood or tissues of viremic livestock, or direct contact with blood and bodily fluids of infected patients. Ticks of the genus Hyalomma are the primary vectors for CCHFV, and the virus is endemic throughout Africa, the Middle East, Eastern

\footnotetext{
*Correspondence: aradaib@Yahoo.com

Department of Clinical Medicine, Molecular Biology Laboratory (MBL), Faculty of Veterinary Medicine, University of Khartoum, P.O. Box 32, Khartoum North, Sudan
}

\section{Biomed Central}

(C) 2013 Adam et al.; licensee BioMed Central Ltd. This is an Open Access article distributed under the terms of the Creative Commons Attribution License (http://creativecommons.org/licenses/by/2.0), which permits unrestricted use, distribution, and reproduction in any medium, provided the original work is properly cited.
Europe, and central Asia [1-10]. Recently, CCHFV has been repeatedly reported as an important emerging infectious viral pathogen in the Kordufan region, Sudan. We reported the first outbreak of CCHF in 2008 among health care workers in Alfulah rural hospital, West Kordufan [11]. Subsequently, another outbreak was reported in 2009 in Donkup village, Abyei District, South Kordufan [12]. Very recently, a nosocomially acquired CCHFV infection was reported in an attending physician in North Kordufan as a result of providing medical care to CCHFV infected patient from Lagawa, an area of endemicity in South Kordufan. However, CCHF has never been recognized in North Kordufan State [13]. Earlier serologic studies have suggested the 
presence of various arboviruses in Sudan, including CCHFV [14,15]. Indirect serologic evidence of CCHFV infection was recorded in camels exported from Sudan to Egypt [16] and in sheep and goats exported to Saudi Arabia [17]. It is well documented that viremia and CCHFV-specific antibodies develop in infected livestock including, sheep, cattle and camels. However, the infection is typically asymptomatic and no clinical hemorrhagic disease appears to be associated with CCHFV in infected livestock [18]. Never the less, infected livestock, particularly cattle could provide virus for tick-borne transmission to highly susceptible humans; thus, play an important role in the epidemiology of the disease [18-20]. It is, therefore, becoming increasingly obvious that the control of emerging viral pathogens, such as CCHFV, is especially important in the Sudan given the large numbers of livestock in the country, and their importance to the national economy and rural communities. Therefore, epidemiologic studies including implementation of improved surveillance are urgently needed to better predict and respond to this devastating disease in the Kordufan region, Sudan [21]. The objectives of the present study were to estimate the prevalence of CCHFV infection and to identify the potential risk factors associated with the disease among cattle in North Kordufan State, Sudan.

\section{Results}

The result of this survey showed that out of 299 animals, 21 were found to be infected with CCHF indicating that the overall prevalence rate was $7 \%$ among cattle in North Kordufan State. The highest and the lowest rate of infection were recorded in Umrawaba (10.3\%) and Abuzabad (3.5\%), respectively. The individual risk factors attributes indicated that older cattle were eight times more likely to be infected with CCHFV $(\mathrm{OR}=8.0824, \mathrm{CI}=1.174-66.317$, $\mathrm{p}$-value $=0.034)$. Cross breeds are highly susceptible to tick infestation and they were at 37 time higher at risk compared to endogenous breed $(\mathrm{OR}=37.06, \mathrm{CI}=1.455-944$, $\mathrm{p}$-value $=0.029)$. The management risk factors attributes showed that highly tick-infested cattle are 6 times higher at risk for CCHF when compared to tick-free animals $(\mathrm{OR}=6.532, \mathrm{CI}=1.042-10.852$, $\mathrm{p}$-value $=0.030)$. The results are summarized in (Table 1). In contrast, there was no

Table 1 Logistic regression analysis showing significant difference $(p<0.05)$ between CCHFV seropositive cattle and risk factors (age, breed and number of tick per animal) associated with the disease in North Kordofan State, Sudan

\begin{tabular}{lccc}
\hline Risk factors & OR & $\mathbf{9 5 . 0 \% ~ C . I}$ & p-value \\
\hline Age & 8.82 & $1.17-66.32$ & 0.034 \\
Breed & 37.06 & $1.46-94.43$ & 0.29 \\
Ticks number & 6.53 & $1.04-10.85$ & 0.030 \\
\hline
\end{tabular}

significant difference between CCHFV seropositive cattle and other individual or management risk factors included in the study such as, animal sex, body condition, animal source, grazing system, other animals in the herd, herd size, farm yard, vector control, tick treatment, tick control, milk production, history of diseases and localities. The results are shown in (Table 2).

\section{Discussion}

Previous studies on experimental CCHFV inoculation of cattle showed that infected animals amplified the virus to a sufficient level to infect the tick vector. The infected cattle developed a low-titre viremia and became seroconverted $[18,22,23]$. Thus, during the viremic stage, cattle can provide virus for tick-borne transmission to highly susceptible humans $[1,24,25]$. This finding suggested that cattle may play an important role in the epidemiology of the disease. In contrast, CCHFV causes highly fatal infection in humans with $30 \%$ mortality. Among different ruminant species present in Sudan, cattle were selected for this study as CCHFV infection appears to occur most frequently in larger mammals, which are the preferred hosts of adult tick vector, Hylomma species [26]. The occurrence of nosocomial $\mathrm{CCHF}$ outbreaks worldwide and the risks these cases pose for medical staff in resource poor health care facilities, necessitate the importance of improved surveillance system for this important emerging viral pathogen [6,11,12,27-30].

In the present investigation, the risk factors that were significant in the univariable model were re-entered in logistic regression whenever a new risk factor becames significant. In the final models, a variable with a P-value $<0.05$ was considered statistically significant. The final

Table 2 Logistic regression analysis showing lack of association ( $p$-value $>0.05$ ) between CCHFV seropositive cattle and other risk factors in North Kordofan state, Sudan

\begin{tabular}{lccc}
\hline Risk factors & OR & $\mathbf{9 5 . 0 \%}$ C.I & p-value \\
\hline Animal sex & 3.03 & $0.66-13.45$ & 0.15 \\
Grazing system & 1.02 & $0.27-38.34$ & 0.99 \\
Body condition & 1.11 & $0.17-7.22$ & 0.94 \\
Animal source & 0.39 & $0.03-5.69$ & 0.49 \\
Other animals & 0.65 & $0.14-2.93$ & 0.57 \\
Herd size & 0.76 & $0.01-1.37$ & 0.99 \\
Farm yard & 2.31 & $0.71-7.57$ & 0.16 \\
Tick problem & 3.5 & $0.03-6.27$ & 0.94 \\
Vector control & 1.92 & $0.13-3.61$ & 0.72 \\
Tick treatment & 0.45 & $0.05-4.49$ & 0.50 \\
Milk production & 1.28 & $0.42-3.97$ & 0.66 \\
Disease history & 0.78 & $0.09-2.37$ & 0.87 \\
Localities & 0.10 & $0.01-4-44$ & 0.24 \\
\hline
\end{tabular}


models of CCHFV seropositive cattle included only three independent risk factors were statistically significant. There was significant difference between the CCHFV infection rate and the age of the animal. When assessing age as risk factor, it was shown that the calves started to get infected with CCHF after the age of 2 years. At this age, the animals are usually released into the pasture for grazing, where they are likely to be exposed to infected tick and subsequent CCHFV infection. We believe that the association of CCHFV infection rate and age is probably attributed to frequent exposure of older cattle to infected tick in the pasture. In contrast, young calves are usually kept indoors and are well taken care of by the animal owners from infectious diseases particularly, tickborne infections. Previous epidemiological surveys indicated that there were higher risks of older cattle for CCHFV infections in different countries including Egypt, Iran and Turkey $[20,23,31]$. In addition, there was also a significant difference between the breed of the animal and CCHFV infection rate. The highest infection rate was observed among cross breeds (high percentage of exotic blood) as they are highly susceptible to tick infestation and subsequent CCHFV infection. In contrast, the indigenous breeds are relatively resistant to tick infestation hence, they were at lower risk for the disease compared to cross breed. Moreover, there was a significant difference between the number of ticks per animal and the rate of the infection with the disease. It is well documented that $\mathrm{CCHF}$ is a tick-borne zoonotic disease and thus, heavily tick-infested cattle are likely to become CCHFV positive by bites of infected ticks [23,25]. Many species of mammals can transmit CCHFV to ticks when they are viremic $[24,25]$. It should also be noted that treatment of cattle with insecticides should be applied monthly to prevent tick infestation. The lack of association between seroprevalence and tick treatment is probably due to the infrequent treatments with insecticides by the nomads specially, under field conditions. This phrase has been inserted into the text of the discussion section. Small vertebrates such as hares and hedgehogs, which are infested by immature ticks, may be particularly important as amplifying hosts [1]. Whereas some avian species such as ostrich can amplify the virus others are refractory to infection but may act as mechanical vectors by transporting infected ticks over a long distance. Migratory birds might spread the virus between distant geographic areas [32,33]. In contrast, the risk assessment studies indicated that there was no significant difference between CCHFV infection and the rest of the individual or management risk factors included in the study. It is worth mentioning that the gender has no significant difference for CCHFV infection among male and females as both sexes are equally infected with the disease. Likewise, there was no significant difference between localities and CCHFV infection rate, suggesting wide distribution of the tick vector all over the localities of North Kordufan.

\section{Conclusions}

The scientific data presented in this study indicated that CCHFV does exist in North Kordufan State and that humans are at risk of becoming infected with the disease. Never the less, an outbreak of CCHF among humans in this region of the Sudan is yet to be reported. It is recommended that livestock attendants and slaughter house workers should consider strict hygienic measures when handling tick-infested livestock or their associated products. The residents have to be aware of the risk of being infected with CCHFV as a result of consumption of uncooked animal-derived products. This is because the social habit of consumption of raw offals of cattle and raw livers of sheep with bile salts and spices (mararah) is not uncommon in different regions of the Sudan, which may serve as a means of transmission of CCHFV [34]. Physicians and medical health workers in North Kordufan should consider this virus in their efforts to diagnose the disease in patients with clinical presentations compatible with those of CCHFV. Future surveillance program for CCHF should be extended to include other susceptible animals such as sheep, goats and camels. In addition, the high-risk human groups (animal attendants, slaughter house workers and butchers), and the distribution of ticks in the region should also be considered to better predict and respond to CCHF outbreak in the State of North Kordufan, Sudan.

\section{Methods}

\section{Study area}

The North Kordofan State is located between longitudes 27.00 and 32.20 East and latitudes $12.12^{\circ}$ and $16.4^{\circ}$ North, occupying an area of 190,840 square $\mathrm{km}$. The State is boarded by North Darfur State in the northwest; Northern State in the north; Khartoum State in the east; White Nile State in the south-east; West Kordofan state in the south-west and South Kordofan State in the south. The total population in North Kordufan is approximately 02.9 million. About $63 \%, 13 \%$ and $24 \%$ are rural, urban and nomadic people, respectively. The livestock population in North Kordufan constitutes one of the major sources of the income to the national economy and rural communities. Recent official livestock population was estimated to be 960,500 for cattle; 7,200,000 for sheep; 3,600,000 for goats; and 1,200,000 for camels. The map of Sudan showing the localities in North Kordufan is shown in (Figure 1).

\section{Study design}

A cross sectional study was conducted to estimate the prevalence rate of CCHF in cattle and to investigate the 


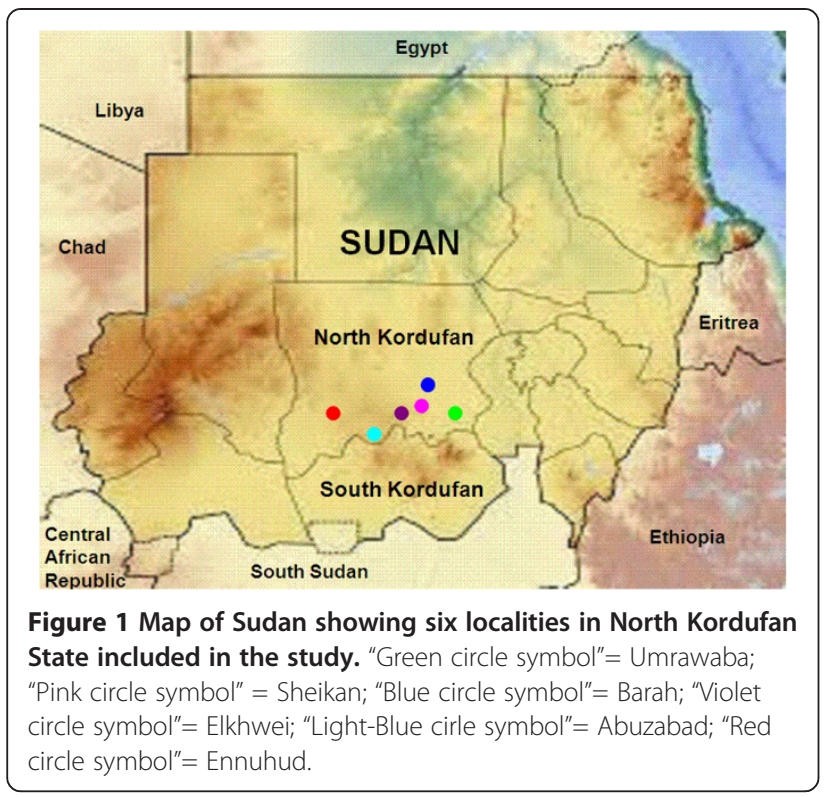

potential risk factors associated with the disease. The multistage probability sampling method was conducted. Six localities in North Kordufan were randomly selected from all nine localities in North kordufan (Figure 1). Two administration units were selected from each locality. Seven villages were selected from each unit. Finally, simple random sampling was applied to choose the animals from each herd [21].

\section{Questionnaire}

A pre-tested structured questionnaire with the primary objective of elucidating the multifactorial background of disease was conducted in an interactive manner at all selected herds. All animals included in this study were subjected to a questionnaire, which was filled out by the animal owners. The questionnaire included individual risk factors attributes age (younger animals $<2$ years, older animals 2 years and above), sex (male, female), breed (indogenous, exotic), previous history of the disease (previous exposure to CCHF, no exposure), body condition (Thin, fats), and management risk factors attributes herd size (small, medium and large), grazing system (nomadic, seminomadicand stationary), milk production (high, low and none), vector control (use of insecticide or not), Tick treatment frequency (less than 1month, 1-3 months and, more than 3 months). The source of each animal in the herd (Raised on farm, Purchased from other farms or Purchased from local market). presence of other animal species in the herd, (the present of other animals such as sheep, goat and camels in the cattle herd). Herd size of cattle (small, medium and large).

\section{Ethical clearance}

The study received ethical clearance from the Research Board of the Faculty of Veterinary Medicine, Sudan
University for Science and technology, Khartoum, Sudan. The risk factor information was obtained from the animal owners through the questionnaire form, which permitted use of the samples for diagnostic and research purposes.

\section{Collection of blood samples}

A total of 299 serum samples of cattle were collected randomly from six localities in North Kordofan state, Sudan. These localities include (Umrawaba, Barah, Sheikan, Ennuhud, Elkhuwei and Abuzabad). Blood samples were collected from the jugular veins in clean sterile vaccutainers and were allowed to clot and sera were separated and kept frozen at $-20^{\circ} \mathrm{C}$ until used.

\section{Enzyme-linked immunosorbent assay (ELISA)}

Indirect enzyme-linked immunosorbent assay (ELISA) was performed to screen the sera for CCHFV-specific immunoglobulin G (IgG) antibodies basically as described by [22]. ELISA was performed in 96-well immunoassay microplates (Nunc, Roskilde, Denmark) and optimal working dilutions of reagents were determined by chessboard titration. Unless stated otherwise, $100 \mathrm{uL}$ test volumes were used, incubations were performed for $1 \mathrm{~h}$ at $37^{\circ} \mathrm{C}$. The plates were washed three times with PBS containing 0 I\% Tween 20 (Merck, Darmstadt, Germany) (PBST), wells were post-coated with 200, ul of PBS containing $2 \%$ bovine serum albumin (Calbiochem, La Jolla, USA), and the diluent for reagents was PBS containing 10\% Skimmed milk (Amba, Denmark). Briefly, the plates were coated with sucrose-acetone extracted CCHFV antigen and incubated overnight at $4^{\circ} \mathrm{C}$. The source of the antigen used is cell lysate from CCHFV Nigeria strain IbAr 10200. The details for the preparation of the CCHFV antigen were basically as described by Mariner et al. [35]. The antigen used in this study was obtained from the Center for Disease Control and Prevention, Atlanta, USA). The plates were washed, and aliquots of test sera (positive and negative controls) were added in separate wells at a dilution of 1:100. After a 1-h incubation, the plates were washed, and rabbit anti-bovine IgG conjugated with horse radish peroxidase (HRP) was added to the plate at a dilution of 1,000 and incubated for $1 \mathrm{~h}$. The plates were then washed and the substrate, 2,2'-azino-bis(3-ethylbenthiazoline-6-sulfonic acid, (Kirkegaard and Perry Laboratories) was added. CCHFV-infected cattle serum sample was incorporated in each ELISA plate as positive control to estimate the higher limit of the sensitivity. Negative control sera were obtained from CCHFV-free animals and from cattle infected with Rift valley fever virus (RVFV), a related viral hemorrhagic fever virus to estimate the lower level of the specificity of the ELISA assay. The results were read either visually or by using ELISA reader set at 
$405 \mathrm{~nm}$. A presumptive diagnosis was made when IgG antibody in the test sample had a significant color change or had higher optical density than the ratio between the positive and negative controls.

\section{Statistical analyses}

The data were entered in computer using statistical package for social sciences (SPSS) software package for window (version 16.0) and double checked before analyses. Logistic regression analyses were performed using the seropostive cattle to CCHFV Ig G as dependent variable and the risk factors as independent variables. Odd ratios and 95\% confidence interval were calculated and $P$ value $<0.05$ was considered significant.

\section{Competing interests}

The authors declare that they have no competing interests.

\section{Authors' contributions}

IAA collected the blood samples and optimized the ELISA for detection of IgG antibodies in cattle sera, and prepared the draft manuscript. MAM collected blood samples designed the study. IEA designed the experiment and prepared the final manuscript. All authors read and approved the final version of the manuscript.

\section{Acknowledgements}

The authors would like to thank Dr. Stuart T. Nichol of the Molecular Biology Laboratory, Viral Special Pathogens Branch, Division of High Consequence Pathogensand Pathology, Centers for Disease Control and Prevention, USA, for provision of CCHFV antigen. The technical assistance of Mr. Abdalla M. Fadlelmoula is gratefully acknowledged. This study received partial financial support from the Scientific Research Directorate of the University of Khartoum, Sudan. The result of this study does not reflect the opinion of the funding sources.

Received: 17 January 2013 Accepted: 29 May 2013

Published: 5 June 2013

\section{References}

1. Swanepoel R, Shepherd AJ, Leman PA, et al: Epidemiological and clinical features of Crimean-Congo hemorrhagic fever in Southern Africa. Am J Trop Med Hyg 1987, 36:120-132.

2. Vesenjak-Hirjan J, Punda-Polic V, Dobe M: Geographical distribution of arboviruses in Yugoslavia. J Hyg Epidemiol Microbiol Immunol 1991, 35:129-140

3. Schwarz TF, Nitschko H, Jager G, Nsanze G, Longson G, Pugh RN, Abraham AK: Crimean-Congo haemorrhagic fever in Oman. Lancet 1995, 346:230.

4. Schwarz TF, Nsanze H, Longson M, Nitschko M, Gilch S, Shurie S, Ameen A, Zahir AR, Acharya UG, Jager G: Polymerase chain reaction for diagnosis and identification of distinct variants of Crimean-Congo hemorrhagic fever virus in the United Arab Emirates. Am J Trop Med Hyg 1996, 55:190-196.

5. Rodriguez LL, Maupin GO, Ksiazek TG, Rollin PE, Khan AS, Schwarz TE, Lofts RF, Smith JF, Noor AM, Peters CJ, Nichol ST: Molecular investigation of a multisource outbreak of Crimean-Congo hemorrhagic fever in the United Arab Emirates. Am J Trop Med Hyg 1997, 57:512-518.

6. Altaf A, Luby S, Ahmed AJ, Zaidi N, Khan AJ, Mirza S, Mc Cormick J, FisherHoch S: Outbreak of Crimean-Congo haemorrhagic fever in Quetta, Pakistan: contact tracing and risk assessment. Trop Med Int Health 1998, 1998(3):878-882.

7. Burt FJ, Leman PA, Smith JF, Swanepoel R: The use of a reverse transcription-polymerase chain reaction for the detection of viral nucleic acid in the diagnosis of Crimean-Congo haemorrhagic fever. J Virol Methods 1998, 70:129-137.

8. Ergonul O: Crimean-Congo haemorrhagic fever. Lancet Infect Dis 2006, 6:203-214.

9. Whitehouse CA: Crimean-Congo hemorrhagic fever. Antiviral Res 2004, 64:145-160
10. Avsic-Zupanc T: Epidemiology of Crimean-Congo hemorrhagic fever in the Balkans. In Crimean-Congo Hemorrhagic Fever: A Global Perspective. Edited by Ergonul OWCA. Dordrecht: Springer; 2007:75-88.

11. Aradaib IE, Erickson BR, Mustafa ME, Khristova ML, Saeed NS, Elageb RM, Nichol ST: Nosocomial outbreak of Crimean-Congo hemorrhagic fever, Sudan. Emerging Infect Dis 2010, 16:837-839.

12. Aradaib IE, Erickson BR, Karsany ME, Khristova ML, Elageb RM, Mohamed MEH, Nichol ST: Multiple Crimean-Congo hemorrhagic fever virus strains are associated with disease outbreaks in Sudan, 2008-2009. PLoS Negl Trop Dis 2011, 5:e1159. doi:10.1371/journal.pntd.0001159.

13. Elata AT, Karsany MS, Elageb RM, Hussain MA, Eltom KH, Elbashir MI, Aradaib IE: A nosocomial transmission of crimean-congo hemorrhagic fever to an attending physician in north kordufan, Sudan. Virol J 2011, 8:303. http://www.virologyj.com/content/8/1/303.

14. Watts DM, Tigani AE, Botros BA, Salib AW, Olson JG, McCarthy M, et al: Arthropod-borne viral infections associated with a fever outbreak in the northern province of Sudan. J Trop Med Hyg 1994, 97:228-230.

15. McCarthy MC, Haberberger RL, Salib AW, Soliman BA, Tigani AE, Khalid Ol, et al: Evaluation of arthropod-borne viruses and other infectious disease pathogens as the causes of febrile illnesses in the Khartoum Province of Sudan. J Med Virol 1996, 48:141-146.

16. Morrill JC, Soliman AK, Imam IZ, Botros BA, Moussa MI, Watts DM: Serological evidence of Crimean-Congo haemorrhagic fever viral infection among camels imported into Egypt. J Trop Med Hyg 1990, 93:201-204.

17. Hassanein KM, El-Azazy A, Yousef HM: Detection of Crimean-Congo haemorrhagic fever virus antibodies in humans and imported livestock in Saudi Arabia. Trans R Soc Trop Med Hyg 1997, 91:536-537.

18. Burt FJ, Swanepool R, Braack LEG: Enzyme-linked immunosorbent assays for the detection of antibody to Crimean-Congo haemorrhagic fever virus in the sera of livestock and wild vertebrates. Epidemiol Infect 1993, 111:547-557. 547.

19. Shepherd AJ, Swanepoel R, Shepherd SP, McGillivray GM, Searle LA: Antibody to Crimean-Congo hemorrhagic fever virus in wild mammals from Southern Africa. Am J Trop Med Hyg 1987, 36:133-142.

20. Garcia S, Chinikar S, Coudrier D, Billecocq A, Hooshmand B, Crance JM, Garin D, Bouloy M: Evaluation of a Crimean-Congo hemorrhagic fever virus recombinant antigen expressed by Semliki Forest suicide virus for IgM and IgG antibody detection in human and animal sera collected in Iran. J Clin Virol 2006, 35:154-159.

21. Martin SW, Meek AH, Willeberg P: Veterinary epidemiology: principles and methods. Ames, lowa, USA: lowa State University Press; 1987:P 45.

22. Dowall SD, Richards KS, Graham VA, Chamberlain J, Hewson R: Development of an indirect ELISA method for the parallel measurement of IgG and IgM antibodies against Crimean-Congo haemorrhagic fever (CCHF) virus using recombinant nucleoprotein as antigen. J Virol Methods 2012, 2:335-341.

23. Mohamed M, Said A, Murad M, Grahard R: A surological survey of Crimean Congo hemorrhagic fever in animal in the Sharkia Governorate in Egypt. Vet Ital 2008, 44:513-517.

24. Swanepoel R, Struthers JK, Shepherd AJ, McGillivray GM, Nel MJ, Jupp PG: Crimean-Congo hemorrhagic fever in South Africa. Am J Trop Med Hyg 1983, 32:1407-1415.

25. Swanepoel R, Shepherd AJ, Leman PA, Shepherd SP, Miller GB: A commonsource outbreak of Crimean-Congo haemorrhagic fever on a dairy farm. S Afr Med J 1985, 68:635-637.

26. Shepherd AJ, Swanepoel R, Leman PA: Antibody response in CrimeanCongo hemorrhagic fever. Rev Infect Dis 1989, 11:801-806.

27. Burney MI, Ghafoor A, Saleen M, Webb PA, Casals J: Nosocomial outbreak of viral hemorrhagic fever caused by Crimean hemorrhagic fever-Congo virus in Pakistan in 1976. Am J Trop Med Hyg 1980, 29:941-947.

28. Ahmeti S, Raka L: Crimean-Congo haemorrhagic fever in Kosova: A fatal case report. Virol J 2006, 3:85.

29. Gurbuz Y, Sencan I, Ozturk B, Tutuncu E: A case of nosocomial transmission of Crimean-Congo hemorrhagic fever from patient to patient. Int J Infect Dis 2009, 13:105-107.

30. Khan AS, Maupin GO, Rollin PE, Noor AM, Shurie HH, Shalabi AG, Wasef S, Haddad YM, Sadek R, ljaz K, Peters CJ, Ksiazek TG: An outbreak of CrimeanCongo hemorrhagic fever in the United Arab Emirates, 1994-1995. Am J Trop Med Hyg 1997, 57:519-525.

31. Lotfollahzadeh S, Nikbakht Boroujeni GH, Mokhber Dezfouli MR, Bokaei S: A Serosurvey of Crimean-Congo Haemorrhagic Fever Virus in Dairy Cattle in Iran. Zoonoses Public Health 2011, 58:54-59. 
32. Deyde VM, Khristova ML, Rollin PE, Ksiazek TG, Nichol ST: Crimean-Congo hemorrhagic fever virus genomics and global diversity. J Virol 2006, 80:8834-8842.

33. Lindeborg M, Barboutis C, Ehrenborg C, Fransson $T$, Jaenson TG, Lindgren PE, Lundkvist A, Nyström F, Salaneck E, Waldenström J, Olsen B: Migratory birds, ticks, and crimean-congo hemorrhagic Fever virus. Emerg Infect Dis 2012, 18:2095-2097.

34. Abu Salma AA: Meat hygiene in the Sudan: Public health implications of edible offals. MVSc thesis: Faculty of Veterinary Medicine, University of Khartoum, Sudan; 1995.

35. Mariner JC, Morill J, Ksiasik TG: Antibodies to hemorrhagic fever viruses in domestic livestock in Niger: Rift Valley fever and Crimean Congo hemorrhagic fever. The American Society of Tropical Medicine and Hygiene. Am J Trop Met Hyg 1995, 53:217-222.

doi:10.1186/1743-422X-10-178

Cite this article as: Adam et al:: A seroepidemiological survey of

Crimean Congo hemorrhagic fever among Cattle in North Kordufan State, Sudan. Virology Journal 2013 10:178.

\section{Submit your next manuscript to BioMed Central and take full advantage of:}

- Convenient online submission

- Thorough peer review

- No space constraints or color figure charges

- Immediate publication on acceptance

- Inclusion in PubMed, CAS, Scopus and Google Scholar

- Research which is freely available for redistribution 